\title{
Electrotomography of the roof rocks in coal seams
}

\author{
Evgeny Saltymakov*, Artem Gerasimov, and Mikhail Tayursky \\ Federal Research Center for Coal and Coal Chemistry SB RAS, 650000, Kemerovo, Russia
}

\begin{abstract}
A comparative analysis of boundaries determined by the initial and integrated geoelectric section with the results of engineeringgeological wells drilling and sampling has been performed. Taking into account the refined boundaries, electrical conductive properties and mining and geological information, geological and geophysical sections were built and the roof condition in the study area was determined.
\end{abstract}

\section{Introduction}

The effective use of innovative technologies to achieve high production rates in the development and mining of deposits by the underground method depends on the selected technologic mode of coal extraction, which in turn is determined by mining and geological conditions $[1,2]$. When mining sloping coal seams, the efficiency of the roof management process has a significant impact on productivity. Most of the excavated areas have a very heterogeneous roof structure. The stability, activity and load properties of the roof depend on its thickness, mineral composition, strength characteristics, mining and hydrogeological conditions of bedding. Due to the fact that these parameters variation is of the wide range within the mining area, the labor intensity for additional measures to control the roof increases as well as the costs conditioned by the complete termination of work in the coal face. To date, measures for the roof management are developed on the basis of a mining and geological forecast, which is formed based on the results of geological exploration. For high-quality information support within the entire mining section, it is necessary to increase the amount of drilling operations, which is economically inexpedient for coal mining enterprises.

For additional exploration of coal seams roof sections, it is effective to use geophysical methods [3], in particular, electrical prospecting. When conducting ground-based deep studies of roof rocks based on significant differentiation of electrical properties at the "rock-coal" boundary, it is most rational to use electrotomography at a low-frequency current. This is also due to the fact that this approach is weakly sensitive to interference generated by mining equipment. However, for a detailed study of the roof rocks state from the surface, characterized by weak differentiation of the electrical properties of the rock layers, it is necessary to achieve a resolution value that will allow for recording such boundaries. The resolving capacity of electrotomography depends on the equipment used

\footnotetext{
*Corresponding author: centr@coal.sbras.ru
} 
and, therefore, on the parameters of the electric current, the measurement technique, in particular, the use of various electrical prospecting installations for electrodes, as well as the model base for the processing process. Even insignificant changes in electrical resistivity values results in these values averaging for even thinner layers or for the coalrock mass elements. Considering these features during the field stage of a coal seam roof ground studies by means of electrotomography, for subsequent office data processing and interpretation of measurement results becomes an urgent issue.

\section{Results and discussion}

The formation of a dismantling chamber under sediments in the rock weathering zone can negatively affect the roof stability and cause additional costs for dismantling of shearers. As part for developing measures to ensure the mining process in the area of extraction column dismantling chamber in one of the coal mines belonging to the Erunakovsky geological and economic region, the study employing electrotomography was performed in order to identify the presence and areal distribution of weakened zones of the coal seam roof. The company's services planned activities to ensure the roof stability in the dismantling chamber area and the following research objectives were formulated:

- engineering and hydrogeological mapping of the coal seam roof in the dismantling chamber area;

- clarification of the site structure;

- registration of area with altered physical characteristics of rocks.

The surveys were carried out in the area with the degas unit installed on the surface and inducting interference. For engineering-geological mapping of the mine allotment section and identification of the presence and areal distribution of coal seam weakened roof zones, studies were carried out on 3 geophysical profiles with a total length of 1,410 m (Fig. 1).

More than 1,587 geophysical observations were recorded in the course of electrical exploration by means of the Skala-48 multi-electrode electrical survey station. Immediately before the measurements start, the electrodes grounding and generated signal level were checked. According to the results of a signal level analysis aimed for undertaking measurements through No. 1-3 profiles, the $120 \mathrm{~W}$ power electric generator to feed the electrodes was selected. Profile No. 1 and No. 2 were arranged from the north-east to the south-west at a distance of $20 \mathrm{~m}$ and $50 \mathrm{~m}$ from the dismantling chamber, respectively.

Profile No. 1 crosses the ventilation entry at $50 \mathrm{~m}$, and the conveyor one at $350 \mathrm{~m}$ mark. Profile No. 2 crosses the ventilation entry at $30 \mathrm{~m}$, and the conveyor at $330 \mathrm{~m}$ mark. Both profiles crossed the technological road (Fig. 2). The profiles line is oriented along the dismantling chamber axis. The length of profiles No. 1 and No. 2 made $470 \mathrm{~m}$ each. Profile No. 3 was drawn across the strike of profiles No. 1 and No. 2 for the reference and a more detailed assessment of the physical and mechanical state of rocks within the study area. This will allow for obtaining additional information in order to improve the accuracy in weakened zones localization and the obtained data interpretation based on a joint analysis of points intersection with profiles No. 1 and No. 2. The length of profile No. 3 resulted in $470 \mathrm{~m}$. 


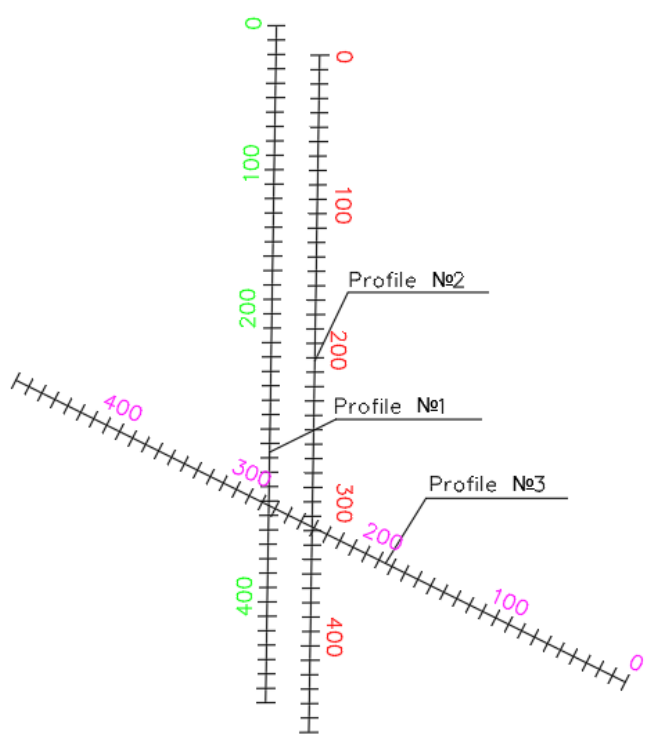

Fig. 1. Location of geophysical lines.

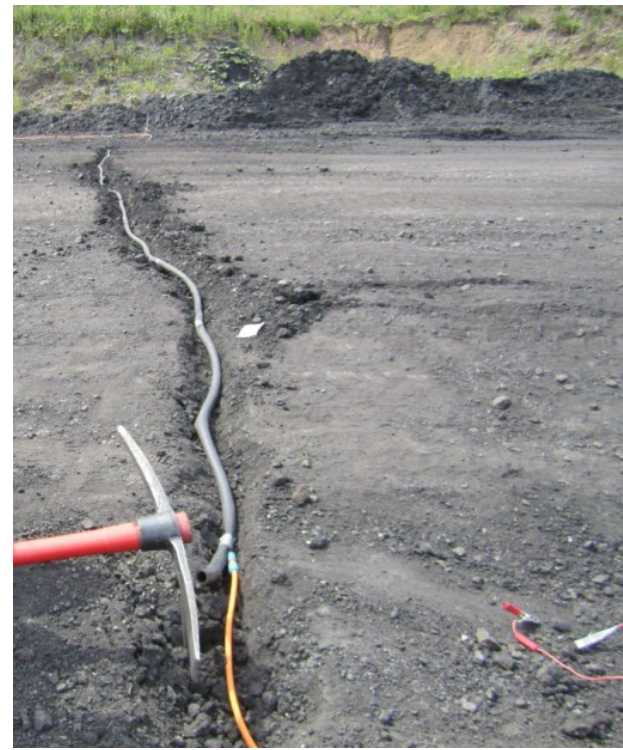

Fig. 2. Laying an electrical prospecting streamer across the technological road.

The processing of the recorded signal as a result of the field stage of research was carried out in two main stages: data preparation (filtration) and geoelectric section plotting. During the recorded information preparation, the analysis and evaluation of the received data array were carried out in relation to induced noise and interference. By now, the filtering process is based on operation in an interactive mode, as a result of which some of useful information often becomes lost (Fig. 3).

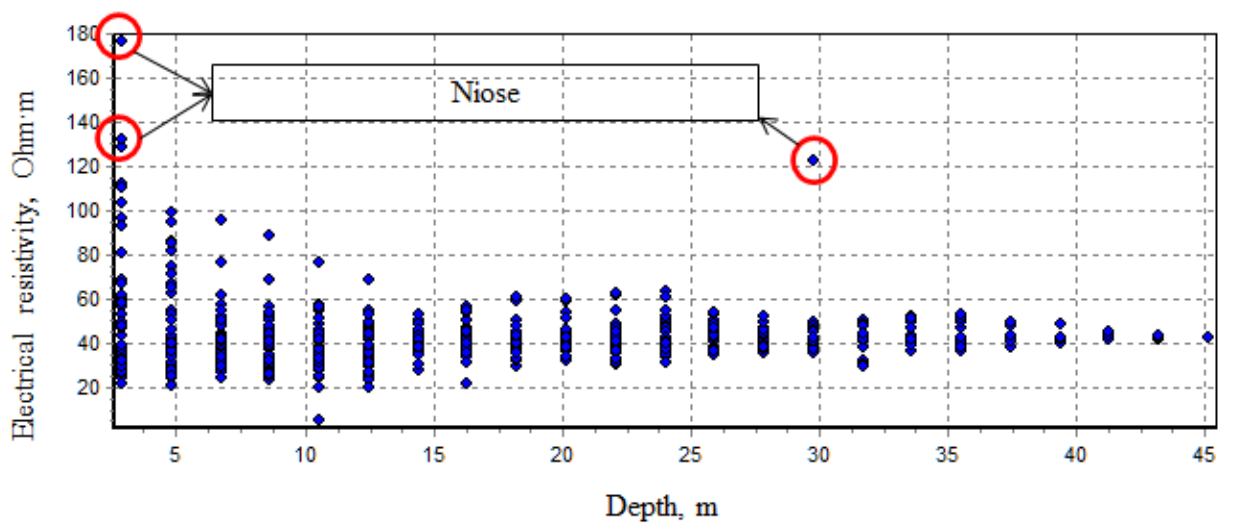

Fig. 3. Graph of the filtration process analysis of the geophysical observations.

Considering the greatest influence of the measuring system geometric parameters (such as a type of electrical prospecting installation, the distance between the electrodes) on the effective depth of research with depth variation, the number of geophysical observations characteristic of a certain type of electrical prospecting installation is constant. Thus, with a depth increase in the geological section study, the density of geophysical observations per unit area of the study area decreases (Fig. 4). Taking into account the above said with 
standard approaches to geophysical data processing the issue of registering objects, the geometric dimensions of which are less than the distance between geophysical observations and the clear boundaries of geological environment layers localization, has not been addressed yet.

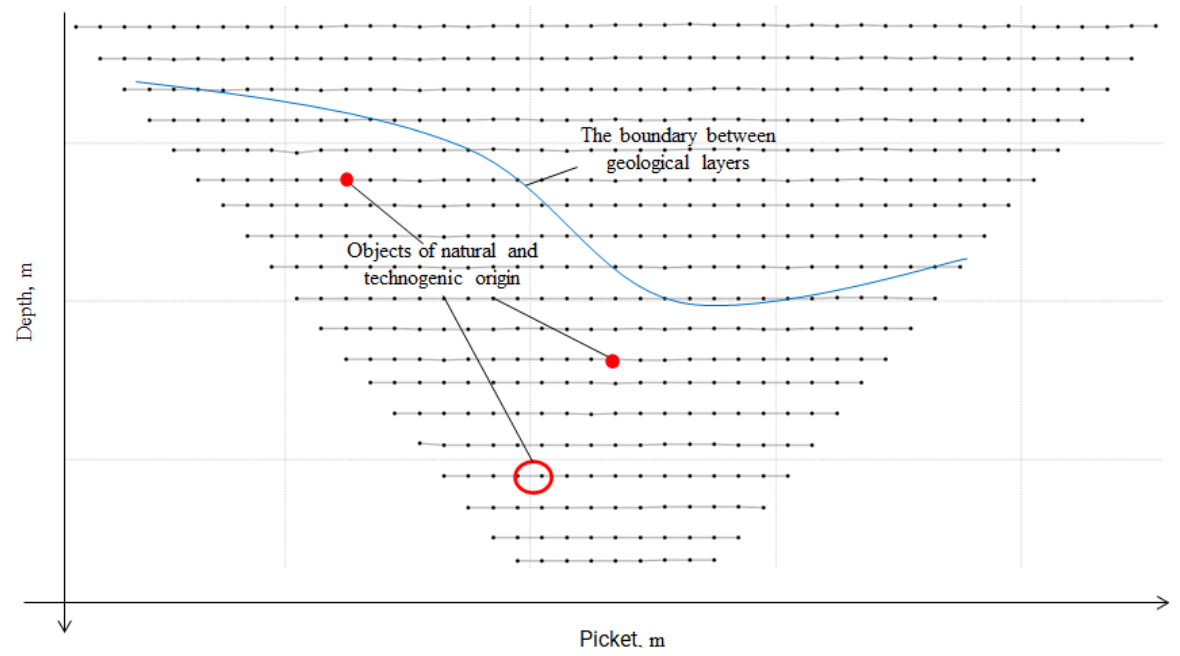

Fig. 4. Schematic representation of a geoelectric section.

Modern software systems are based on addressing the direct issue of electrical prospecting for calculating the values of specific electrical resistivity. As a result of a geoelectric section plotting, by means of inversion based on the least squares method, an array of specific resistivity values is obtained, which is much larger than the number of geophysical observations, visualized as a color model of the rock mass.

The developed approach for plotting a geoelectric section based on electrotomography data makes it possible to localize the rock massif layers boundaries and objects that are not related to the geological environment, and is based on an algorithm that includes the division of original geoelectric section into areas with specified geometric dimensions (Figure 5). Within these boundaries, the values of specific resistivity are integrated, which correspond to the smallest element (in graphical form, a pixel), and its average value within the region boundaries is determined.

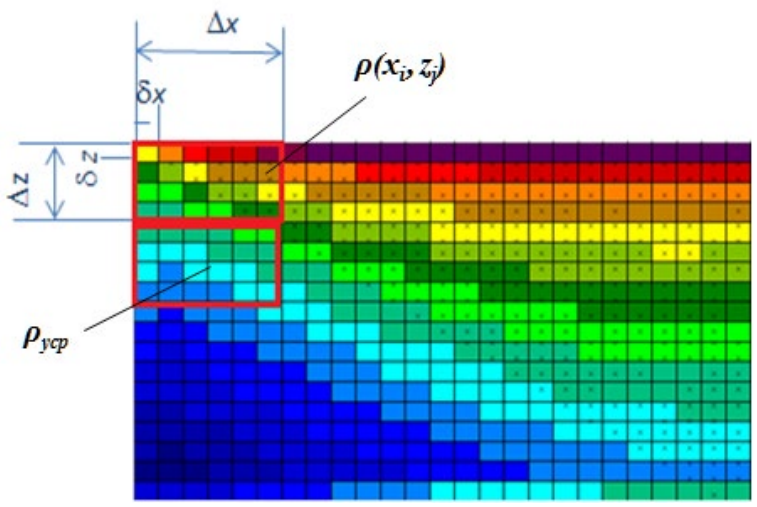

Fig. 5. Diagram of algorithm implementation for plotting an integrated geoelectric section: $\Delta x, \Delta z$ dimensions of the geoelectric section elements; $\delta x$, $\delta h$ - pixel sizes; $x, h$-coordinates, $\rho$ - specific electrical resistivity; $\rho_{\text {yсp }}-$ integrated value $\rho ; \mathrm{n}$ - number of section elements 


$$
\rho_{\text {ycp }}=\frac{1}{n} \sum_{i=1}^{\Delta x} \sum_{j=1}^{\Delta z} \rho\left(x_{i}, z_{j}\right)
$$

Based on measurement results (Fig. 6a) using the developed approach, a fragment of the integrated geoelectric section was plotted (Fig. 6c). From the obtained data array, a line of maximum change in specific electrical resistance was found, which characterizes the boundary "rocks of the Quaternary age - bedrocks" (Fig. 6b).

a)
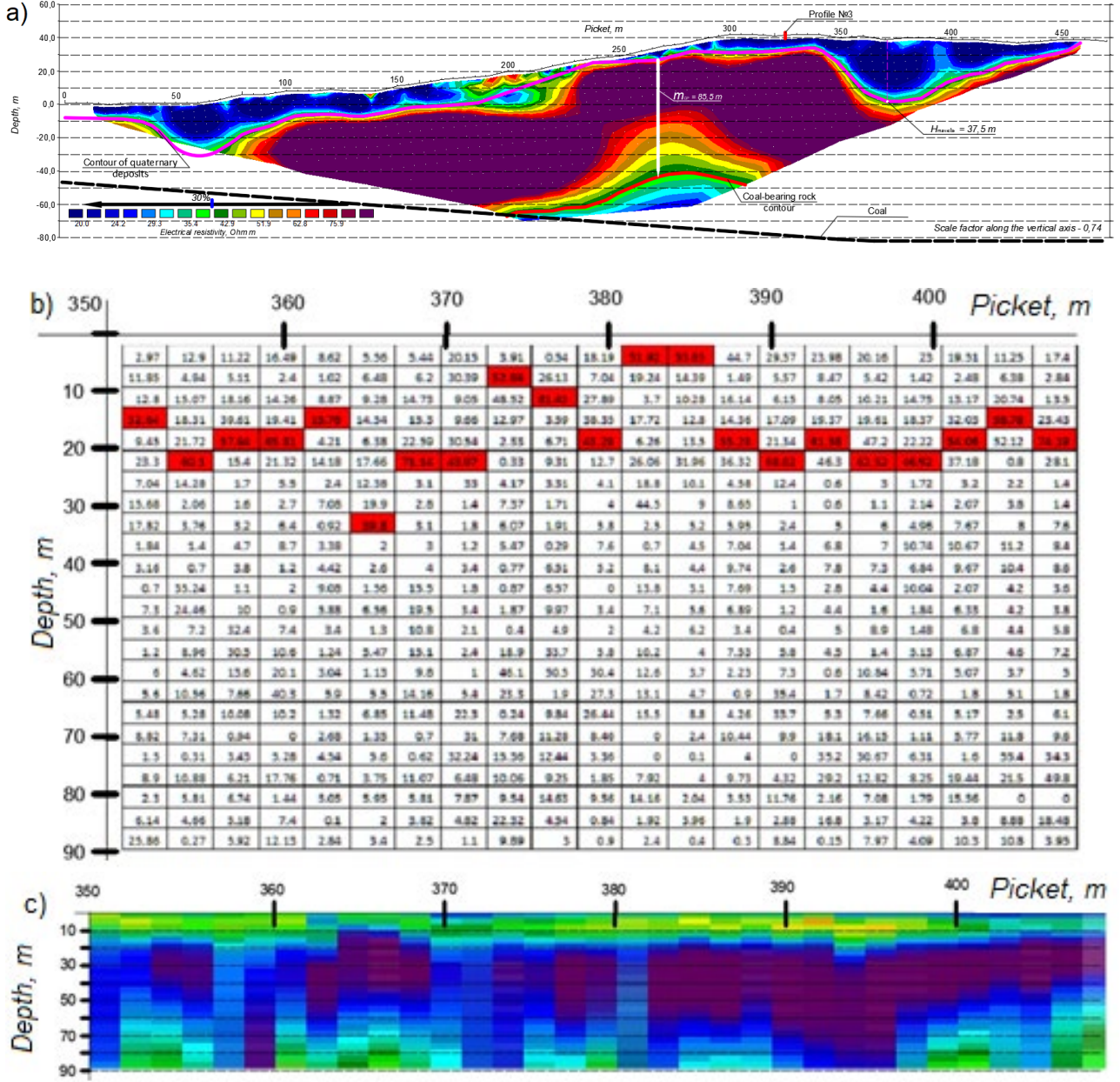

Fig. 6. Determination of the boundary "Quaternary rocks - bedrocks" by means of the developed algorithm for integrated geoelectric section plotting: a), b) table for defining the boundary "rocks of the Quaternary age - bedrocks"; c) fragment of the integrated geoelectric section.

A comparative analysis of engineering survey data with sampling and the results of initial geoelectric section interpretation and the plotted section using the developed approach, with regard of mining and geological information, has been carried out. As a result of the analysis using the developed approach, it was found that the boundary of the "Quaternary rocks - bedrocks" is localized closer to the boundary established during exploration drilling (Fig. 7). 
However, the insignificant results divergence is presumably due to the fact that drilling and electrical tomography were performed at different time intervals, in the period between which the rock mass was deformed under the influence of natural forces and as a result of mining operations. Also, errors associated with the construction of a geological section in the inter-well interval are not excluded. The contour of coal-bearing rocks is defined in a similar way.

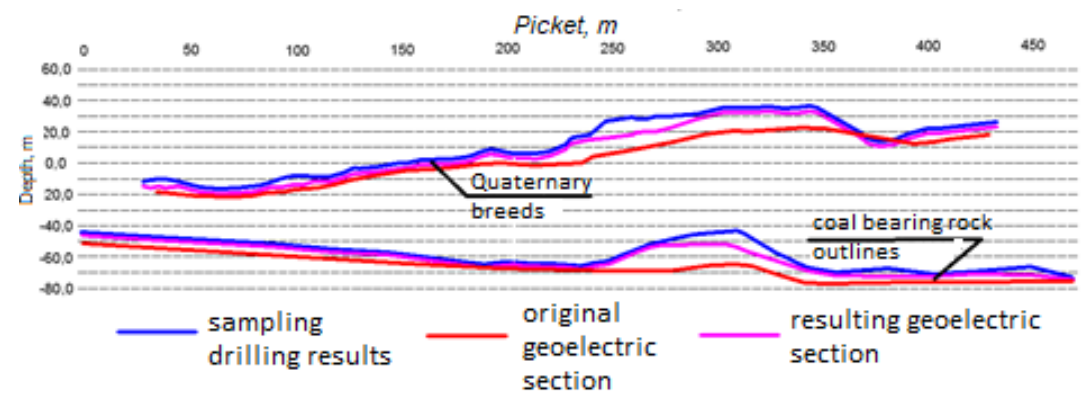

Fig. 7. Comparison of results obtained during the integrated geoelectrical section interpretation with original sampling drilling data

In the course of mining and graphic documentation analysis and the results of electrical exploration, it was found that the dismantling chamber was formed in the hazardous zone of increased rock pressure from the edge parts of the pillar of the overlying and worked-out coal seam. In a danger zone, the roof rocks stability is sharply reduced, the formation of falls, domes, "shooting" from the coal face front is possible.

Based on the data obtained by the electrical tomography method undertaken along the lines of geophysical profiles No. 1-3, the structure features and physical and mechanical state of the active roof in the area of the dismantling chamber, which determine its stability, were assessed, including: lithological composition, the presence of weakened zones, water cut, etc. (Fig. 7) and are placed on the surface plan [7, 8].

a)

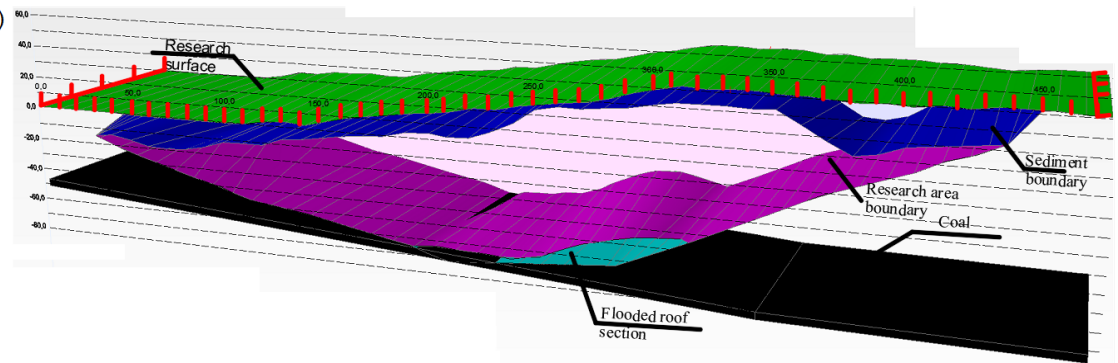

b)

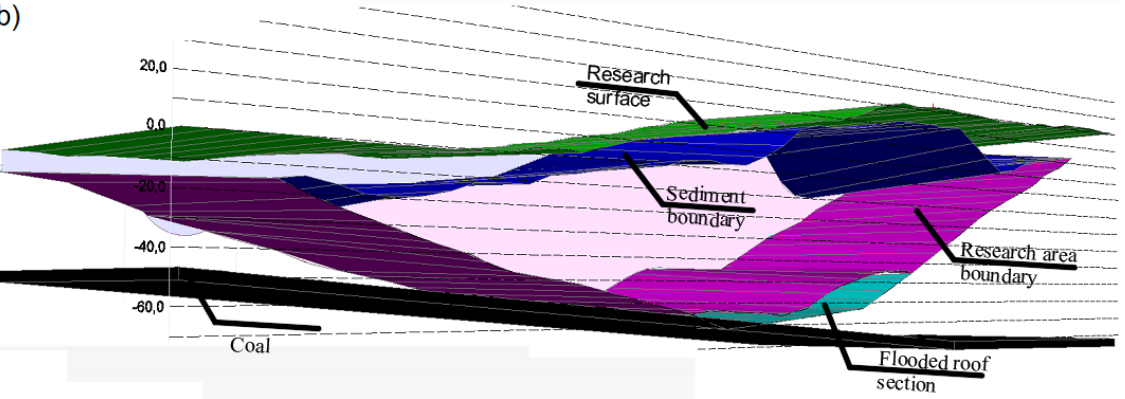




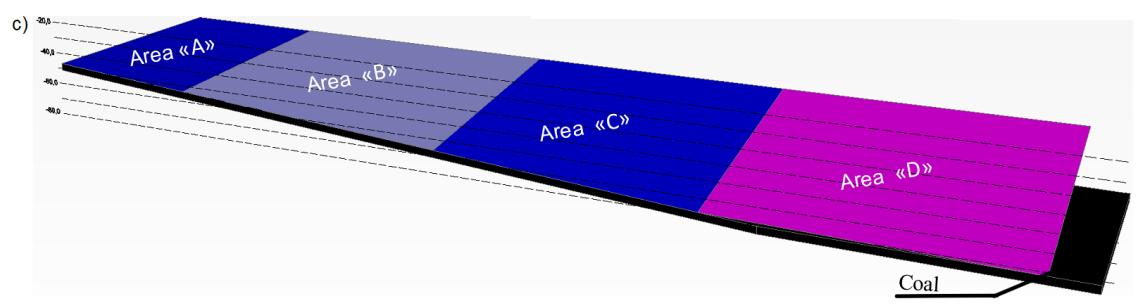

Fig. 8. Results of electrotomography for two parallel and one transverse profiles: a), b) visualization of geological and geophysical section in $3 \mathrm{D} ; \mathrm{c}$ ) coal seam roof sections.

Section "A": The specific resistivity of the coal seam roof changes from 0 to $40 \mathrm{Ohm}$ • $\mathrm{m}$, which characterizes the presence of a flooded roof. The immediate roof, presumably, is represented by flooded moderately stable or completely unstable siltstone (average specific resistivity is $30 \mathrm{Ohm} \cdot \mathrm{m}$ ). Possibly the presence of a false roof composed of low-resistivity siltstone (fine-grained siltstone with low electrical resistivity - less $30 \mathrm{Ohm} \cdot \mathrm{m}$.

Section "B": The specific resistivity of the roof varies from 30 to $200 \mathrm{Ohm} \cdot \mathrm{m}$, this is due to the absence of flooded areas. The main roof is composed of sandstone (average resistivity $-110 \mathrm{Ohm} \cdot \mathrm{m}$ ) and siltstone (average resistivity $-70 \mathrm{Ohm} \bullet \mathrm{m}$ ). The immediate roof is represented by moderately stable or completely unstable siltstone (average specific resistivity $-50 \mathrm{Ohm} \cdot \mathrm{m}$ ). The presence of a false roof composed of unstable carbonaceous siltstone is possible (the average value of specific resistivity is $30 \mathrm{Ohm} \cdot \mathrm{m}$ ).

Section "C": The specific resistivity of the roof varies from 10 to $40 \mathrm{Ohm} \cdot \mathrm{m}$, which characterizes the presence of a flooded roof. The immediate roof, presumably, is represented by watered moderately stable or completely unstable siltstone (average resistivity is $30 \mathrm{Ohm} \cdot \mathrm{m}$ ). Possibly the presence of a false roof composed of low-resistivity siltstone.

Section "D": Roof specific resistivity varies from 40 to $220 \mathrm{Ohm} \cdot \mathrm{m}$. The main roof is composed of sandstone (average specific resistivity $-130 \mathrm{Ohm} \cdot \mathrm{m}$ ) and siltstone (average resistivity $-90 \mathrm{Ohm} \cdot \mathrm{m})$. The immediate roof is represented by moderately stable or completely unstable siltstone (average resistivity - $50 \mathrm{Ohm} \cdot \mathrm{m}$ ). Concepts of the fracture system development under hydrodynamic impact a rock mass made it possible to assess the nature of their propagation. The results of mathematical modeling analysis showed the comparability of the full-scale experiment with the model. In the future, it is planned to adapt the model to quantify the methane amount released from fractures into the borehole.

\section{Conclusions}

The main goal of the Long-term program for the coal industry development in Russia for the period up to 2030 is to increase mining volumes. To achieve the goal of improving the safety system of mining operations, it is necessary to introduce modern technologies for exploration, development, excavation column preparation, production, transportation, and geocontrol. In particular, the formation of an assembly and dismantling chamber in areas of natural and man-made rock mass requires not only a specific approach to the development of design solutions, but also reliable information on the composition and condition of the rock mass, which is a contour for mine workings.

Analysis of the experience of basic geophysical methods practical application demonstrated that the most effective tool for solving a wide range of engineering problems due to the significant differentiation of the electromagnetic properties of the rock mass, are the methods of electromagnetic control. When studying the main methods of electromagnetic control, taking into account the study goal, the location of the field stage, the type of source and the nature of the signal it generates, the characteristics of the object 
of research, the required parameters, the registered components and the details of the studies in relation to the determination of the physical and mechanical state of the roof rocks of the coal seam it was found that it is expedient to use the DC resistance method in the modern modification of electrotomography.

It was found that with the selected parameters of the measuring system, considering the depth of the anomalous zone bedding and the complexity of the survey surface topography, which do not always allow for achieving a sufficient density of geophysical observation points for a reliable assessment of the physical and mechanical properties, in this case, the coal seam roof rocks zone in the area of the planned dismantling chamber, it is necessary to carry out a series of measurements with a decrease in the distance between the electrodes to increase the value of the density of recording points.

The developed approach for modifying the initial geoelectric section into an integrated one allows for localizing the boundaries of the rock mass layers and objects that are not associated with the geological environment, and is based on an algorithm that includes dividing the region of original geoelectric section into regions with specified geometric dimensions and integrating the specific resistivity values that correspond to the smallest element, and determining its average value within the boundaries of the region The effectiveness of the approach has been proven in the course of a comparative analysis of engineering survey data with sampling and the plotted integrated section.

The developed approach for data processing made it possible, together with the specialists of the coal mining enterprise, to develop a set of measures for shearer dismantling the mechanized complex, including the use of a sheave and additional hydraulic supports during dismantling. To increase the stability of the dismantling chamber in the area of increased rock pressure in the roof of the interchamber pillar, it is recommended to install linings, the ends of which are attached to the roof rocks using anchors. Based on the results of the electrical exploration studies, the expediency of using electrotomography and the developed approach for assessing the parameters of the coal seam roof sections from the surface in difficult operating conditions of the coal mining enterprise was confirmed.

\section{References}

1. A.P. Sadov, V.N. Kosterenko, et al., Coal, 12, 61-67 (2015)

2. O.V. Tailakov, D.N. Zastrelov, et al., GIAB, OB6, 170-176 (2013)

3. O.V. Tailakov, S.V. Sokolov, E.A. Saltymakov, Science-intensive technologies for the development and use of mineral resources, 4, 437-441 (2018)

4. S. Szalai, A.Novak and L. Szarka, JEEG, 14(1), 15-23 (2009)

5. A.A. Bobachev, A.A. Gorbunov, I.N. Modin, V.A. Shevnin. Instruments and systems of exploration geophysics, 02, 14-17 (2006)

6. M.H. Loke, R.D. Barker, Geophysical Prospecting, 44, 131-152 (1996)

7. O.V. Tailakov, E.A. Saltymakov, et al., Industrial Safety, 1, 30-34 (2016)

8. O.V. Tailakov, E.A. Saltymakov, et al., Bulletin of KuzSTU, 6, 5-12 (2017) 